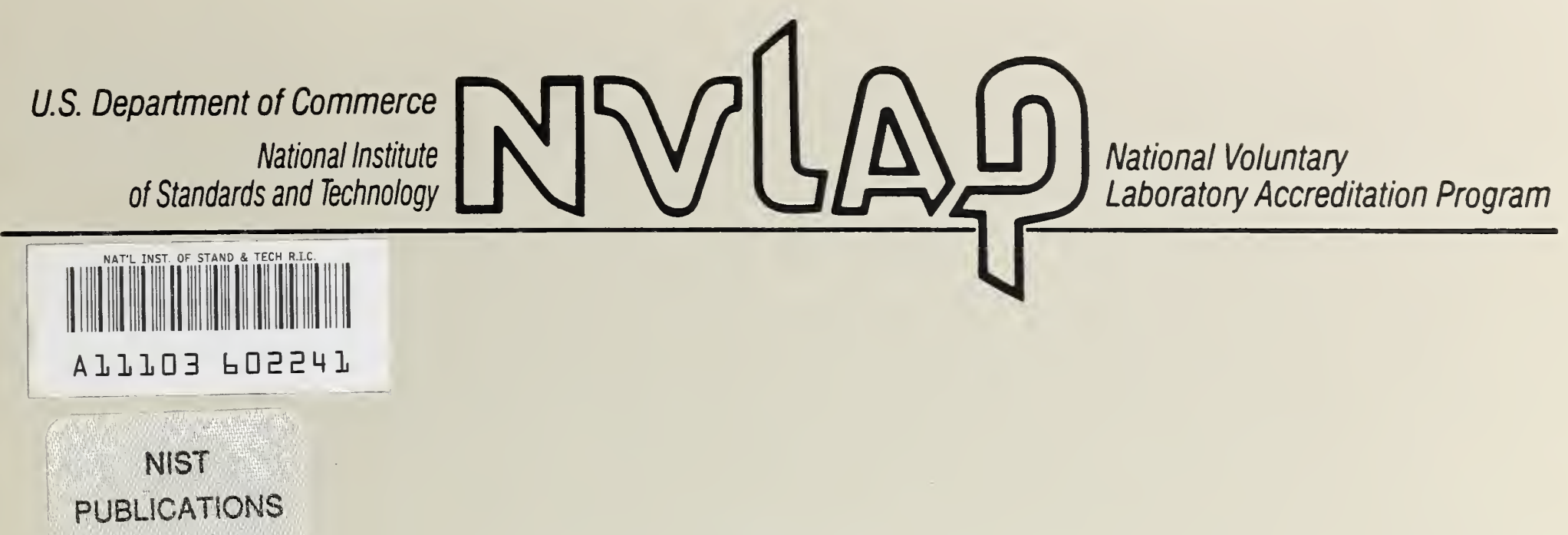

\title{
NVLAP \\ FY 90 ANNUAL REPORT
}

NISTIR 4599

June 1991

QC

100

.456

\#4599

1991

C. 2
U. S. DEPARTMENT OF COMMERCE

National Institute of Standards and Technology

Gaithersburg, Maryland 20899 
NATIONAL INSTITUTE OF STANDARDS \&

TECHNOLOGY

Research Information Center

Gaithersburg, MD 20899 


\title{
NVLAP \\ FY 90 ANNUAL REPORT
}

\author{
Vanda R. White, Editor \\ Nancy M. Trahey, Chief \\ Laboratory Accreditation Program
}

National Voluntary Laboratory Accreditation Program

National Institute of Standards and Technology

Gaithersburg, MD 20899

NISTIR 4599

June 1991

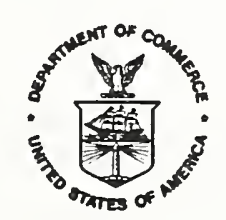

U. S. DEPARTMENT OF COMMERCE

Robert A. Mosbacher, Secretary

Robert M. White, Under Secretary for Technology

National Institute of Standards and Technology

John W. Lyons, Director 



\section{LABORATORY ACCREDITATION PROGRAM}

\section{Introduction}

The Laboratory Accreditation Program consists of the National Voluntary Laboratory Accreditation Program (NVLAP), the largest multipurpose accreditation program within the federal government. Totally supported by the fees it collects from applicant laboratories, NVLAP offers accreditation in 11 major program areas covering some 26 testing specialties. These areas include acoustics, asbestos fiber analysis, carpets, commercial products, computer applications, construction, electromagnetic compatibility and telecommunications, personnel radiation dosimetry, secondary calibration for ionizing radiation, solid $f$ uel room heaters and thermal insulation. Table 1 shows NVLAP's technical and financial activity for Fiscal Year (FY) 1990. As can be seen, NVLAP increased its accreditations by $42 \%$, its income by $51 \%$ and its expenses by $60 \%$ over the previous year.

Table 1. Summary of Key Operating Data

(as of year end)

\begin{tabular}{|c|c|c|c|}
\hline & FY 89 & FY 90 & $\Delta \%$ \\
\hline Income * & $\$ 2,227,317$ & $\$ 3,357,403$ & $+50.7 \%$ \\
\hline Expenses & $\$ 2,100,308$ & $\$ 3,353,864$ & $+59.7 \%$ \\
\hline Staffing (FTEs) & 10.0 & 14.5 & $+45.0 \%$ \\
\hline \# Accreditations & 698 & 991 & $+42.0 \%$ \\
\hline
\end{tabular}

* Income in excess of expenses includes monies collected in one fiscal year for work to be completed (and monies expended) in the following fiscal year.

** Includes main facilities and sub-facilities. A laboratory accredited in both PLM and TEM is counted as two accreditations.

\section{The National Voluntary Laboratory Accreditation Program (NVLAP)}

NVLAP was established in 1976 by the National Bureau of Standards (now the National Institute of Standards and Technology) to evaluate the competency of laboratories to perform specific tests or types of tests. Competency is defined as the ability to meet NVLAP conditions and to conform to criteria as identified in and tailored to the test methods selected for accreditation. The actual process of accreditation involves periodic on-site assessment of laboratory operations and management as well as frequent participation in proficiency testing programs.

The NVLAP critical elements for accreditation are developed through a public process which allows everyone (laboratory, regulator, customer) with an interest in the testing activity, the opportunity to contribute. Additionally, the specific technical requirements of the accreditation must be based on recognized standards, which are themselves usually developed by a consensus process. Once incorporated in with the critical elements, the accreditation requirements are then imposed uniformly on every laboratory applying for that particular technical accreditation.

NVLAP contracts with recognized experts in the various technical fields covered by its programs, to perform the required on-site assessments. All experts are instructed by NVLAP 
in the conduct of assessments and are provided checklists and other material which will enable them to be thorough and, at the same time objective, in the conduct of their work. These experts then submit detailed reports of their assessment observations to NVLAP. On the basis of their reports, NVLAP determines what further courses of action are warranted and then notifies the laboratories. It is emphasized to all applicant laboratories that NVLAP technical experts have no authority to determine their accreditation status; only the Chief of NVLAP can make such a determination.

NVLAP proficiency testing programs are likewise operated for NVLAP by organizations selected for their expertise in such activities. These organizations design and develop statistically appropriate testing regimes for NVLAP's approval, prepare and distribute the test samples, collect and technically evaluate the data and submit the information to NVLAP who determines the individual performances and assigns pass/fail grades to the participant laboratories. Depending on this grade and the outcome of the on-site assessment (when required), a laboratory's accreditation may be granted, renewed, suspended, revoked or denied. NVLAP accreditation is valid for one calendar year and must be renewed annually. The date given on the NVLAP Certificate of Accreditation is the expiration date of the accreditation.

\section{FY 90 Accomplishments}

The technical scope and magnitude of NVLAP's activities increased substantially in FY 90, and there is every indication that the increase will continue into FY 91 and beyond. While rate of growth in NVLAP programs has been steady over its fifteen-year history, only in the past two years has that growth so expanded as to severely tax available staff. Of necessity, NVLAP has had to proceed with a number of changes in its operational $f$ unctions in order to handle the large influxes of laboratories into its new programs. Most of these changes were made in FY 90 while maintaining the high quality of NVLAP technical activities and responding quickly and appropriately to the ever-growing needs of accreditation as a tool of international commerce and trade. 


\section{NVLAP OPERATIONS}

NVLAP processed some 1100 applications and granted 991 accreditations to testing facilities located in 49 states, the District of Columbia, and 4 foreign countries in FY 90 . Figure 1 shows an analysis of NVLAP activities during FY 90. Figure 2 shows NVLAP accreditations granted in FY 90 by state.

As might be expected, the additional work required to service the growth in accreditation activity substantially taxed the resources of the NVLAP staff which numbered 10 persons at the beginning of the fiscal year. Over the course of FY 90, additional staff members were hired to assist with NVLAP's increased workload, which was particularly heavy in the operations area. At the end of the fiscal year, NVLAP numbered 14.5.

The heightened interest in laboratory accreditation was also manifested in the receipt of a large number of telephone and mail requests for information about accreditation in general and for specific NVLAP programs. The total number of requests was up about $50 \%$ over the previous year. Table 2 summarizes the number of requests received by category. To handle all these requests, a new NVLAP brochure was prepared and additional copies of the individual program handbooks and the Annual Directory printed for distribution. These documents were provided at no charge.

Table 2. Major Categories of Information Requests

Annual NVLAP Directory
$\begin{array}{cc}\text { Asbestos Program: } \\ \text { PLM } & 316 \\ \text { TEM } & 125\end{array}$

Other Programs

Family Circle Article*
204

180

* In the February 1, 1990, issue of Family Circle, an article entitled "Health Hazards in the Home" stated that a free copy of EPA-accredited asbestos detection laboratories was available from NVLAP upon request.

\section{Blanket Purchase Agreement System}

Beginning in March 1990, efforts were initiated to change the method by which NVLAP contracts for Technical Experts' services. Under the old system, personal services contracts were awarded and Technical Experts were paid on a cost reimbursable basis after the completion of a task. Under the new Blanket Purchase Agreement (BPA) system, a Technical Expert is required to prepare a bid for a specific task. If the bid is determined to be reasonable, the NVLAP project leader informs the Technical Expert to proceed with the task.

In early August, a pilot program was implemented to test run the BPA procedures and identify any problems. Ten Technical Experts from the Asbestos Program were chosen to work under the new system. Several tasks were performed, some problems were identified, and solutions developed. 
The advantages of the BPA contracts to NVLAP are:

(1) Less paperwork for the Technical Experts to complete and submit to Accounting;

(2) Ease of implementation for new Technical Experts;

(3) Contracts which do not have to be renewed every year;

(4) No annual maximum dollar limit on Technical Experts' services;

(5) Faster turn-around-time on payments to Technical Experts.

Many of the rough edges initially discovered with the implementation of the pilot program have been smoothed out and the procedures have been improved to carry out more efficiently the requirements of the BPA contract. The true test will come in FY 91 when approximately 600 on-site Asbestos Program assessments must be completed and all costs for them must be negotiated by NVLAP.

\section{NVLAP Information System}

The number of laboratories participating in the NVLAP program has more than quadrupled since the advent of the Asbestos program two years ago. In FY 89 and FY 90, considerable strain was placed upon operational, financial, and managerial control functions, as the existing information system could barely keep pace with the rapid growth of information requirements. Although additional personal computers and sof tware were purchased to accommodate staff growth, a pressing need to more fully integrate the NVLAP functions became evident. Since continued growth is anticipated with the addition of new laboratory accreditation programs, it was decided that a study was necessary to determine the technical requirements for a new NVLAP Information System (NIS).

In FY 90, a preliminary set of objectives was compiled for the NIS. Included in this set were objectives to improve the quality of service to all NVLAP "customers," to increase the productivity of NVLAP as a whole, and to provide adaptibility to accommodate future change and growth. Furthermore, the Budget Office specified that the NIS must interface with any financial systems developed by them and the Office of the Comptroller.

A meeting was held with personnel from the NIST Information Systems Division (ISD) to determine what NIST programming resources were available to NVLAP. A member of the ISD staff visited NVLAP on several days to gather information about its operations and to make recommendations concerning the type and amount of programming expertise and assistance required. Upon review of these recommendations by ISD and NVLAP staff, it was agreed that the best course of action would be to obtain the services of a programmer/analyst, through contract to NVLAP.

FY 91 plans include the selection of a contractor to work on the project in conjunction with a more detailed needs assessment. In addition, an agreement must be reached as to the minimum information requirements to be served by a new system. This will pose a significant challenge because of the diversity of the different laboratory accreditation programs; e.g., the Asbestos program has 2 test methods and over 800 labs, and the Commercial Products Program has 284 test methods and 10 labs. A major goal of FY 91 will be to have a system designed, complete with sof tware and hardware requirements, by the end of the year. 

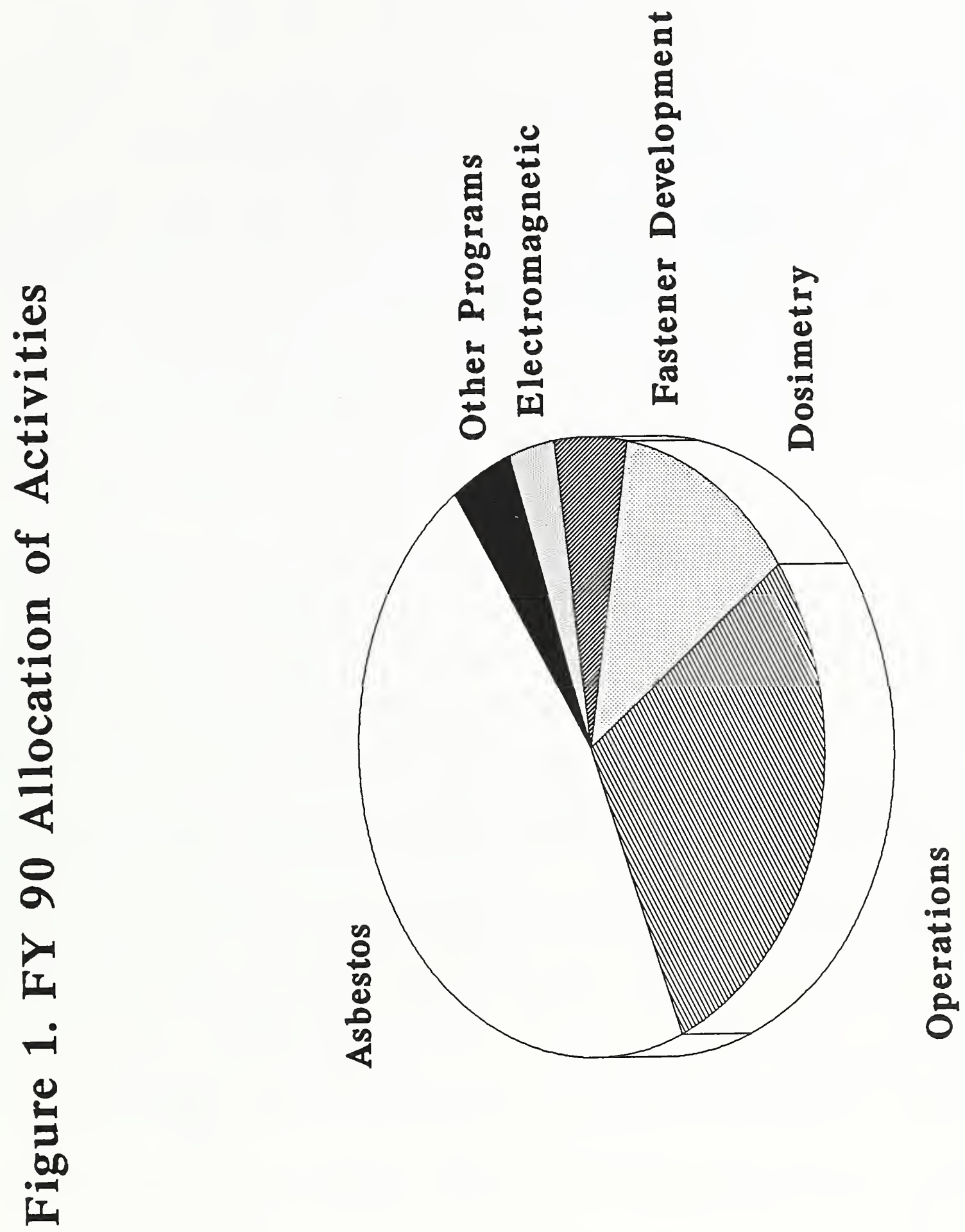
羟

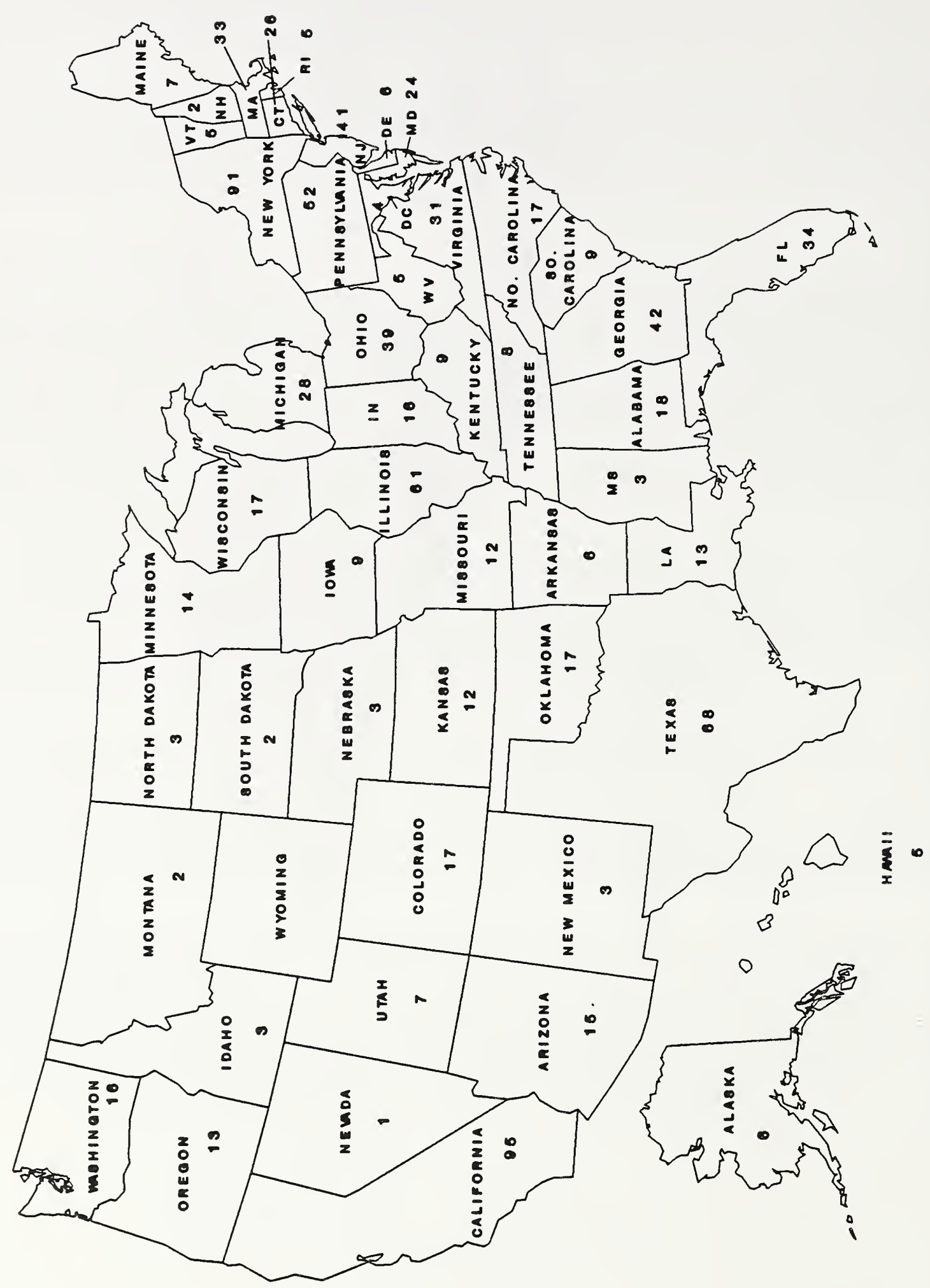




\section{TECHNICAL ACTIVITIES}

The impetus towards greater emphasis on testing and certification as important components of international commerce, resulted in greater public interest in accreditation activities during FY 90. Since accreditation and testing are interrelated, the ramifications of accreditation at the international level became a critical issue to the U.S. Government and individual accrediting bodies, such as NVLAP, especially as regards to its dealings with the accreditation systems of other countries. This was underscored when NVLAP, as part of a U.S. Government delegation, journeyed to Brussels in June 1990 to discuss with the European Community (EC92), testing and certification issues as they pertain to regulated products. In the course of those discussions, NVLAP gave a presentation on its activities. The meeting itself helped to clarify some issues and bring new ones to light. In view of the European activities developing under EC92, NVLAP decided to develop and implement a strategy for assuring that the laboratories it accredits, will be able to compete effectively and fairly with other testing facilities accredited in the EC and elsewhere in the world. To accomplish this, an intensive NVLAP review of all international standards and guides pertinent to its accreditation procedures, current mutual recognition agreements and future activities was initiated. This review will be completed in mid-FY 91.

The increasing use of accreditation as a regulatory tool involved NVLAP in several new activities during the year. The most extensive one, in terms of staff attention, concerned future NVLAP implementation of Congressional legislation written to prevent the manufacture, distribution and sale of fraudulently-produced, substandard fasteners. NIST was asked to provide technical assistance in preparing a final written version which was presented to the Senate for passage. As of the end of FY 90, it had not been brought to a vote in the Senate and though time until the closing of the 10lst Session of Congress was short, passage in this session was nonetheless expected. [Note: The bill passed in late October and was signed into law by the President in mid-November, 1990.]

The Congress is considering two other bills which would mandate initiation of a new NVLAP program. The bills require a laboratory accreditation program to deal with lead-based paint and related hazardous products.

NVLAP was also asked to set up programs in several technical areas not now covered in its existing programs. The requests for these new accreditation activities were contained in letters to the Director of NIST. Those deemed to meet NVLAP's requirements for setting up new programs as outlined in 15 CFR 7, are to be announced in early FY 91 via Federal Register notices inviting public comment. Several other requests made directly to NVLAP and acted upon, involved the addition of new test methods or the establishment of new subcategories of tests in existing programs. Two of the new subcategories developed were the GOSIP program within Computer Applications and the Plumbing Fixtures program within Commercial Products.

Individual descriptions of the new activities initiated by NVLAP in FY 90 follow.

\section{Airborne Asbestos Analysis}

By October 1, 1989, NVLAP had received 111 applications for the TEM Airborne Asbestos Program. On December 15, 1989, the first TEM on-site assessment was completed. By the end of FY 90, 137 more assessments had been completed. The reports from these assessments, along with the laboratories' responses, were reviewed by several Technical Expert Review Panels which met throughout the year to determine if all concerns had been satisfactorily resolved. In some cases, laboratories were notified that they must undergo another on-site assessment. 
In addition to the on-site assessments, proficiency testing samples were sent out to laboratories in February 1990. Prior to the first round of proficiency testing, a practice "round-robin" was conducted. The experience gained showed that consistent evaluation of proficiency tests, and indeed, consistent interlaboratory performance, would be possible only with more specific counting instructions than those found in the AHERA regulations. Such instructions were provided with the first round of proficiency testing.

Upon receipt of the proficiency testing results, a thorough review was undertaken which showed that the instructions were valuable technically in producing consistent and quality measurements. However, the complexity of the review and the of $f$ icial incorporation of the instructions into the TEM method became issues which could not be fully resolved before initial accreditation was due to be granted; therefore, it was decided by NVLAP that initial TEM accreditation would be based only on a successful on-site assessment, which included a demonstration of technical competence. In order to maintain accreditation, laboratories will be required to successfully participate in all future scheduled rounds of proficiency testing.

On July 30, 1990, the first accreditations for the TEM Airborne Asbestos Program were granted to 105 laboratories. Another 22 laboratories have since received accreditation, bringing the total of accredited TEM laboratories to 127 out of 153 enrolled laboratories. The remaining laboratories which have not yet received their accreditation are either new applicants or must still respond to outstanding deficiencies.

\section{Secondary Calibration for Ionizing Radiation}

The criteria committee met in September and approved a final draft of both a technical criteria document and an assessment checklist. Preliminary preparations have been made with the Ionizing Radiation Division of NIST to conduct proficiency testing. The qualifications of thirteen individuals are being reviewed for consideration as assessors. Application materials are being prepared and are expected to be distributed by December 1990.

\section{Plumbing}

The Commercial Products Testing Program, established in 1984, provides for purchasing authorities' specification of testing in accredited laboratories in their contracts for vendor products. This program was expanded in FY 90 to include plumbing (plastics, fixture fittings and fixtures).

Provisions for plumbing laboratory accreditation were responsive to inquiries and requests initially related to the need for energy and water conservation programs by the California Energy Commission (52 FR 18592-18593, dated May 18, 1987) and subsequently, supported by responses from public review. Current needs for plumbing testing accreditation were identified in letters from: (1) the Department of Housing and Urban Development (HUD) concerning application to the requirements for data from test laboratories in HUD Use of Materials Bulletin 73 for product certification, and (2) the national plumbing consultant/chairman of the ASME/ANSI A112 Committee. These letters specifically designated ANSI Z124 plastic plumbing fixtures standards series.

The program is expected to be fully operational in early 1991.

\section{Computer Applications Testing}

Two new programs were developed in the Computer Applications Testing area. Both program areas were requested by the National Computer Systems Laboratory (NCSL) at NIST. NCSL is responsible for developing U.S. Governmentwide Standards for computer sof tware, data communications networks and related telecommunications systems. The new programs will 
accredit laboratories that test to the Government Open Systems Interconnection Profile (GOSIP) and to the Portable Operating System Interface for Computer Environment (POSIX).

In FY 90, both programs were brought to the stage of being ready for application by laboratories. With cooperation among NVLAP, NCSL, and industry groups, NVLAP Program Handbooks, TE Manuals, on-site assessment checklists and other necessary tools were developed.

Early in FY 91, the first group of applicant laboratories will be brought into the program, assessed and accredited to the relevant test method standards. Plans are already being made to incorporate periodic upgrades to those standards.

\section{Fasteners}

The Fastener Quality Act requires establishment of a NIST laboratory accreditation program (LAP) for fasteners (defined for purposes of the Act to include specific kinds of fasteners expected to be used in critical applications). The Act provides for the use of NVLAP procedures in the development and operation of the Fastener LAP. NVLAP has completed initial planning activities in anticipation of passage by the Congress and Presidential signature.

Several subfields of accreditation will be offered, since fastener testing involves a wide range of expertise and neither all laboratories nor assessors possess the total capability. Likely subfields would include chemical, dimensional, mechanical and metallurgical testing.

The technical development plan makes use of both the NIST technical resources as well as research associates from interested and involved companies and organizations. Tasks are formulated to provide the basis for evaluation of laboratory competency to include: the critical elements for test methods (e.g., facilities and equipment, calibration, staffing, and quality system and procedures); assessor checklists; Fastener LAP handbook; and prof iciency testing program.

An initial Federal Register Notice will be issued in early 1991 to inform the industry and laboratories of the requirements of the Fastener Quality Act and provide NIST with information needed to develop a program. Information being sought will include the number and type of laboratories seeking accreditation, and the specifications and test methods being applied to fastener quality control and acceptance testing. Qualified individuals (selection criteria provided in the Notice) will be asked if they are willing to be considered for a NVLAP technical expert position.

\section{Calibration}

NVLAP and Physical Measurement Services Program (PMSP) staff have begun preliminary discussions and planning strategies on how to best develop and implement a laboratory accreditation program for calibration laboratories. The impetus for such a program is coming from: (1) laboratories desiring NIST recognition of their programs, (2) laboratory client demands for competency assurance, (3) domestic regulatory requirements, and (4) international trade requirements being imposed by EC92.

It is expected that this program will initially address five areas of metrology (voltage, mass, length, thermometry, and microwave). A committee will be formed to provide NVLAP with technical assistance and consultation in developing the criteria for the program. The committee will represent a cross section of the industry and include laboratories, laboratory users, technical experts, regulatory officials and general interest groups. 


\section{Future Program Developments}

The following activities may lead to new or expanded programs:

(1) Lead-Based Paint. Congressional legislation introduced in the 101 st Session for NVLAP program development for accreditation of laboratories that perform analyses of lead in paint, soils and dust, is anticipated to be reintroduced.

(2) Lighting Equipment. The National Electrical Manufacturers Association (NEMA) Lighting Equipment Division initiated discussions with NVLAP that will result in a request for an Electric Lighting Products and Systems Accreditation Program (ELPSAP). Collaboration with NIST staff efforts from the Department of Energy (DoE) sponsored lighting research and performance standards preparation in the Center for Building Technology (CBT) is foreseen. Technical support from those specialists for assistance in formulating the specific NVLAP accreditation technical criteria and later inclusion of new test methods, derived from the investigations as NVLAP-specific test methods for accreditation, will be planned.

(3) Radon. The American Association of Radon Scientists and Technologists (AARST) requested the development of a laboratory accreditation program for radon test laboratories. NIST has responded and offered to host an informal workshop, based on the AARST suggestion, and noted the importance of including interested and responsible agencies (to be invited) with technical programs in radon measurements; e.g., the Environmental Protection Agency, the Department of Energy, and Bureau of Mines. An agenda would include progress on voluntary standards that would form the basis of a NVLAP accreditation program if further advancement towards such a development were undertaken.

(4) Wood-Derived Products. The National Particleboard Association requested the development of a laboratory accreditation program. An informal meeting of representatives from woodderived products was held to discuss the breadth of any proposed activities and how to best serve the different interested organizations. HUD has expressed interest in the potential use of such a program. A list of laboratories is being compiled that will be used to obtain a survey of the list of test methods and standards commonly used by laboratories across the variety of processed wood-derived manufactured products. 
APPENDIX

NVLAP ORGANIZATIONAL CHART

(as of FY 90 year-end)

\begin{tabular}{|l|l|}
\hline $\begin{array}{l}\text { Margaret Musick } \\
\text { Secretary }\end{array}$ & $\begin{array}{l}\text { Nancy M. Trahey } \\
\text { Chief }\end{array}$
\end{tabular}$\quad$\begin{tabular}{l|}
$\begin{array}{l}\text { Kristi Garrott } \\
\text { Admin. Officer }\end{array}$ \\
\hline
\end{tabular}

David Alderman

Project Leader

Leslie King

Clerk - Ty pist

Tom Davis

Asst. Project Leader

Maria Lancaster

Clerk - Typist

Lawrence Galowin

Project Leader

Hazel Richmond

Computer Assistant

Robert Gladhill

Project Leader

Lisa Warfield

Financial Assistant

Jeffrey Horlick

Project Leader

Vanda White

Operations Analyst

Paul Martin

Asst. Project Leader

Wayne Stiefel

Project Leader 


\section{STAFF MEMBERS}

(All staff positions are full-time/permanent unless otherwise noted.)

Nancy M. Trahey, Chief, NVLAP, (301) 975-4017

Margaret G. Musick, Secretary, (301) 975-4016

- Timekeeper

- Foreign Travel

Kristi Garrott, Administrative Support Assistant, (301) 975-3879

- Monitors All Financial Information

David Alderman, Project Leader, (301) 975-4019

- Asbestos (Airborne and Bulk)

Tom Davis, Assistant Project Leader, (301) 975-6499

- Asbestos (Airborne and Bulk)

Lawrence S. Galowin, Project Leader, (301) 975-4022

- Carpet

- Commercial Products

- Thermal Insulation

- Solid Fuel Room Heaters (Stoves)

- Plumbing

Robert L. Gladhill, Project Leader, (301) 975-4018

- Acoustics

- Construction Testing

- Dosimetry

- Secondary Calibration Laboratories

Jeffrey Horlick, Project Leader, (301) 975-4020

- Computer Applications Testing

- Electromagnetic Compatibility and Telecommunications

- Proficiency Testing

- NVLAP Editor

Leslie King, Clerk-Typist, (301) 975-4042

- Work Coordinated through Secretary

- Assistance to Administrative Officer and Financial Assistant

- Storeroom Liaison

Maria Lancaster, Clerk-Typist, (301) 975-4042

- Assistant to Project Leaders

- Mail Log/Distribution

- Secretary Back-up

Paul Martin, Assistant Project Leader, (301) 975-3679

- Acoustics

- Construction Testing

- Dosimetry

- Secondary Calibration Laboratories 
STAFF MEMBERS (continued)

Hazel Richmond, Computer Assistant, (301) 975-3024

- Database Information

Wayne Stiefel, Project Leader, (301) 975-4011

- Fasteners

Lisa Warfield, Financial Assistant, (301) 975-3308

- Financial Information

Vanda White, Operations Analyst, (301) 975-3592 (Part-Time)

- Information Management System Coordinator

- Forms Liaison

- Information Documents 



\section{OUTPUTS AND INTERACTIONS}

\section{Publications}

Galowin, L. and Swaffield, J., "Water Efficient Plumbing Fixtures Through Standards and Test Methods," CONSER V 90. The National Conference and Exposition Offering Water Supply Solutions for the 1990s, pp. 179-183, 1990.

Gladhill, R. L., "Impact of Accreditation on Laboratory Quality Assurance," Test Quality for Construction. Materials and Structures/Proceedings of the International RILEM/ILAC Symposium, pp. 283-289, 1990.

Gladhill, R. L., Program Handbook: Construction Testing Services, National Institute of Standards and Technology, NISTIR 89-4039, updated June 1990.

Gladhill, R. L. and Martin, P. R., Program Handbook: Acoustical Testing Services, National Institute of Standards and Technology, NISTIR 4428, October 1990.

Horlick, J., Several articles in A View Toward EMC Excellence, printed by the National Association of Radio and Telecommunications Engineers, April-July 1990 issue.

Horlick, J., Program Handbook: Electromagnetic Compatibility MIL STD 462, National Institute of Standards and Technology, draft, August 1989 (updated August 1990).

Horlick, J., Program Handbook: POSIX FIPS Conformance Testing, National Institute of Standards and Technology, draft, July 1990.

Horlick, J., Program Handbook: GOSIP Conformance Testing, National Institute of Standards and Technology, draft, August 1990.

Horlick, J., ed., Calibration Manual for Electromagnetic Compatibility Test Laboratories, draft, August 1990.

Horlick, J., ed., Quality Assurance Manual for Electromagnetic Compatibility Test Laboratories, draft, August 1990.

Trahey, N. M., Horlick, J. and White, V. R., 1990 Directory of NVLAP Accredited Laboratories, National Institute of Standards and Technology, NISTIR 90-4280, March 1990.

\section{Talks and Presentations}

Galowin, L., "Low Water Usage Fixtures," Panelist, American Supply Association, Las Vegas, NV, October 12, 1989.

Galowin, L., Poster Presentation on NVLAP Plumbing Accreditation, CONSERV 90 Exposition on Water Supply Solutions, Phoenix, AZ, August 12-16, 1990.

Galowin, L. and Swaffield, J., "Effects of Low Fixture Flows on Drainage Systems," American Society of Sanitary Engineers - Refresher Course, Las Vegas, NV, October 13, 1989.

Galowin, L. and Swaffield, J., "Water Efficient Plumbing Fixtures Through Standards and Test Methods," CONSERV 90, National Conference on Water Supply Solutions, Phoenix, AZ, August 15, 1990. 
Galowin, L. and Swaffield, J., "Plumbing Research in Standards and Test Methods for Plumbing Test Laboratory Accreditation," American Society of Sanitary Engineers - Ref resher Course, Keystone, CO, August 31, 1990.

Gladhill, R. L., "NVLAP Update," Panasonic Annual Users Meeting, Keystone, CO, June 1990.

Horlick, J., "NVLAP," NIST/NCSL GOSIP Public Workshop, Gaithersburg, MD, November 1989.

Horlick, J., "NVLAP," NAVAIR E ${ }^{3}$ Progress Review Meeting, Jacksonville, FL, May 1990.

Horlick, J., "NVLAP," NIST/NCSL POSIX Public Workshop, Gaithersburg, MD, July 1990.

Horlick, J., "NVLAP," IEEE International Symposium, Washington, DC, August 1990.

Stiefel, W., "NVLAP Accreditation," National Advisory Committee for Contractor Accreditation, Dallas, TX, November 27, 1989.

Stiefel, W., "NVLAP Accreditation," Aerospace Industries Association, Washington DC, April $5,1990$.

Stiefel, W., "NVLAP Accreditation," Interagency Working Group on Problem Parts and Suppliers, Arlington, VA, July 20, 1990.

Trahey, N. M., "NVLAP," ACIL Forum, Washington, DC, February 12, 1990.

Trahey, N. M., "NVLAP," A2LA Forum, Baltimore, MD, April 30, 1990.

Trahey, N. M., "NVLAP, the FCC and the EMC Directives," U. S. Government Delegation to the EC, Brussels, Belgium, June 13, 1990.

Trahey, N. M., "Briefing on Accreditation Portion of U. S. Government/EC Meetings," ANSI EC92 Workshop, Washington, DC, June 25, 1990.

Trahey, N. M., "Review of Basic Accreditation Criteria," EPA Fact Finding Committee, Washington, DC, August 9, 1990.

Trahey, N. M., "NVLAP Overview," Briefing for EURATOM Visitors, Gaithersburg, MD, August 31, 1990.

Trahey, N. M., "NIST and NVLAP - National and International Ramifications of Accreditation," Briefing for Dr. Lyons, Gaithersburg, MD, September 4, 1990. 


\begin{tabular}{|c|c|c|}
\hline \multirow{3}{*}{$\begin{array}{l}\text { NIST-114A } \\
\text { (REV. 3-90) }\end{array}$} & \multirow{3}{*}{$\begin{array}{l}\text { U.S. DEPARTMENT OF COMMERCE } \\
\text { NATIONAL INSTITUTE OF STANDARDS AND TECHNOLOGY } \\
\text { BIBLIOGRAPHIC DATA SHEET }\end{array}$} & $\begin{array}{l}\text { 1. PULUCATION OR REPORT MUMEER } \\
\text { NISTIR } 4599\end{array}$ \\
\hline & & 2. PERFORMING ORQANIZATION AEPOAT NUMBER \\
\hline & & $\begin{array}{l}\text { 3. PUEUCATIONPATE } \\
\text { June } 199 I^{-}\end{array}$ \\
\hline
\end{tabular}

4. TITLE AMD SUBTITLE

NVLAP FY 90 Annual Report

5. AUTHOR(S)

Vanda R. White, Editor

6. PERFORMING ORCANIZATION (IF JOINT OR OTHER THAY MIST, SEE INSTRUCTIONS)

U.S. DEPARTMENT OF COMMERCE

MATIONAL INSTITUTE OF STANDARDS AND TECHMOLOQY

OATHERSBURG, MD 20090

7. CONTRACT/GRANT NUMBER

9. SPONSORIMG ORQAMIZATION MAME AND COMPLETE ADDAESS (STREET, CTT, STATE, ZIP)

10. SUPPLEMEMTARY NOTES

11. ABSTRACT (A 200-WORD OR LESS FACTUAL SUMMARY OF MOST SIOMIFICANT IMFORMATION. HF DOCUMENT INCUDES A SIGNIFICANT EHBUOGRAPHY OR UTERATURE SURVEY, MENTION IT HEAE)

The NVLAP FY 90 Annual Report summarizes activities of the National Voluntary Laboratory Accreditation Program (NVLAP) for the fiscal year which ended September 30, 1990. The report covers NVLAP Operations, Technical Activities, Staffing, Publications, Talks and Presentations. The Technical Activities section presents individual descriptions of areas of new activity in FY 90 (Airborne Asbestos Analysis, Secondary Calibration for Ionizing Radiation, Plumbing, GOSIP, POSIX, Fasteners, and Calibration), as well as a summary of future program developments.

12. KEY WOROS (B TO 12 ENTRIES; NPHABETICAL ORDER; CAPTALEE OMLY PROPEA MAMES; AMD SEPANATE KEY WORDS OY SEMICOLONS)

accreditation; annual report; asbestos; calibration; computer applications; fasteners; NVLAP; operations; plumbing; publications; seeondary ealibration; staff; talks; technical activities

FON OFFICUL OISTREUTION. DO MOT REIEASE TO MATHOMLL TECHMICAL IMFORMATHON SERMCE (NTIS).

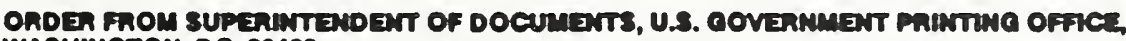
WASHMOTOM, DC 20102

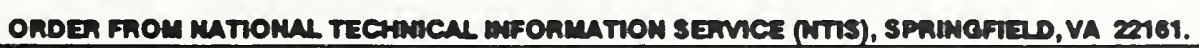

14. MUMEER OF PAINTED PAOES 19

15. Pace

$\mathrm{A02}$

ELECTRONIC FORM 


